\title{
OR-6
}

\section{Optimization of SC-CO Extraction OF Alpinia Galangal (L.) Wild and Estimation of Cost of Manufacturing (COM) Via SIMULATION Process}

\author{
Saidatul Husni Saidin ${ }^{1, *}$, Nor Azah Mohamad Ali ${ }^{1}$, Mailina Jamil ${ }^{1}$, Ireneo Kikic ${ }^{2}$, Alberto Bertucco ${ }^{3}$, \\ Muhammad Faridz Zoll Patah ${ }^{1}$ and Dario Solinas ${ }^{2}$ \\ ${ }^{1}$ Herbal Product Development Programme, Natural Products Division, Forest Research Institute Malaysia (FRIM) \\ 52109 Kepong, Selangor; ${ }^{2}$ Department Of Industrial Engineering \& Information, University Of Trieste, Piazzale Europa \\ 34127 Trieste, Italy; ${ }^{3}$ Department Of Industrial Engineering \& Information, University Of Padova, Padova, Italy; \\ E-mail: saidatul@frim.gov.my
}

In this study, the rhizome of a ginger plant, Alpinia galangal (L.) Wild, was subjected to supercritical fluid carbon dioxide (SC$\mathrm{CO}_{2}$ ) extraction at $150-250$ bar and $40-60^{\circ} \mathrm{C}$. Influence of the operating parameters; temperature and pressure on the yield extract was investigated as well the evaluation of 1-acetoxy-chavicol acetate (1'ACA) content in the best extraction condition by Gas Chromatograph (GC) and Gas Chromatograph/Mass Spectrum (GC/MS). Density of $\mathrm{CO}_{2}(\mathrm{~kg} / \mathrm{L})$ was calculated using Bender correlation based on the pressure and temperature, therefore solubility of solute in $\mathrm{SC}-\mathrm{CO}_{2}(\mathrm{~g} / \mathrm{L})$ can be determined. $\mathrm{PRO} / \mathrm{II}{ }^{\circledR}$ software was used to simulate the extraction process at large scale and to estimate the cost of manufacturing $(\mathrm{COM})$ at the best extraction condition. For simulation process, correlation between solubility of solute in $\mathrm{SC} \mathrm{CO}_{2}$ and $\mathrm{SC} \mathrm{CO}_{2}$ density was calculated based on Chrastil correlation and Peng Robinson was used as the thermodynamic model. The aim of this work is to determine the best SC- $\mathrm{CO}_{2}$ extraction condition for A.galangal rhizome based on yield extract and perform the economical evaluation of the extraction via simulation process.

Keywords: Supercritical fluid carbon dioxide, Extraction, Alpinia galangal, Simulation. 